\title{
Propagação de oliveira 'Koroneiki' pelo método de estaquia em diferentes épocas, concentrações de AIB e presença de folhas
}

\author{
Gener Augusto Penso ${ }^{1 *}$, Marcos Robson Sachet ${ }^{1}$, Luana Aparecida Castilho Maro ${ }^{2}$, \\ Leonardo Silva Patto ${ }^{1}$ Idemir Citadin ${ }^{1}$
}

$10.1590 / 0034-737 X 201663030012$

\section{RESUMO}

Objetivou-se, com este trabalho, avaliar as influências da época, da concentração de AIB e da presença de folhas na propagação por estaquia da oliveira 'Koroneiki'. Estacas de $10 \mathrm{~cm}$ de comprimento foram retiradas da porção mediana de ramos de plantas de três anos de idade, na Universidade Tecnológica Federal do Paraná, entre junho de 2013 e março de 2014. O experimento foi conduzido no delineamento inteiramente ao acaso, com quatro repetições de dez estacas, sendo um fatorial triplo [épocas (junho, setembro, dezembro, março); número de pares de folhas $(0,1$ e 2$)$ e concentração de AIB (0, 1.000, 2.000 e $\left.\left.3.000 \mathrm{mg} \mathrm{L}^{-1}\right)\right]$. O tratamento com AIB consistiu na imersão rápida da base da estaca, por cinco segundos, seguida do plantio em tubetes com substrato comercial. Após, as estacas permaneceram em câmara úmida, sob nebulização, por 60 dias. Decorrido este período, mensuraram-se a sobrevivência (\%), a formação de calos (\%), o número de brotos por estaca e o enraizamento (\%). Para maiores sobrevivência, formação de calo e enraizamento é necessária a manutenção de, pelo menos, um par de folhas nas estacas. A estaquia em dezembro não é recomendada, independentemente das técnicas auxiliares utilizadas. Sem a utilização de AIB, recomenda-se realizar a estaquia em junho e setembro, desde que mantido um par de folhas. Para a estaquia realizada em março, deve-se manter pelo menos um par de folhas, em combinação com doses de 2.000 ou $3.000 \mathrm{mg} \mathrm{L}^{-1}$ de AIB.

Palavras-chave: Olea europaea L., estaquia, enraizamento de estacas.

\section{ABSTRACT \\ Spread of 'Koroneiki' Olive by the cutting method at different times, AIB concentrations and the presence of leaves}

This study aimed to evaluate the influence of timing, IBA concentration and presence of leaves on propagation by cutting of 'Koroneiki' olive. Cuttings of $10 \mathrm{~cm}$ length were collected from the middle portion of branches of three-year-old plants at the Federal Technological University of Paraná, between June 2013 and March 2014. The experiment was carried out in a completely randomized design with four replications of 10 cuttings each, in a triple factorial [timing (June, September, December, March); number of pairs of leaves (0, 1 and 2) and IBA concentrations (0, 1,000, 2,000 and 3,000 mg $\left.\mathrm{L}^{-1}\right)$ ]. The IBA treatment consisted in fast immersion of the cutting base for 5 seconds, and then planted in tubes containing commercial substrate. Thereafter, the cuttings were maintained in intermittent mist condition for 60 days. At the end of this period, the survival (\%), callus formation (\%), number of shoots per cutting and rooting (\%) were measured. For higher survival, roots and callus formation, it is necessary to maintain at least one pair of leaves on the cuttings. It is not recommended to propagate by cutting in December, regardless of the auxiliary techniques. Without the use of IBA, it is recommended to perform the cuttings in June and September, keeping a pair of leaves. For cuttings carried out in March, at least a couple of leaves must be kept, in combination with doses of 2.000 or 3,000 mg L-1 IBA.

Key words: propagation; Olea europaea L.; cuttings.

\footnotetext{
Submetido em 05/08/2014 e aprovado em 29/01/2016.

${ }^{1}$ Universidade Tecnológica Federal do Paraná, Pato Branco, Paraná, Brasil. generpenso@gmail.com; marcos.sachet@gmail.com; leonardosilvapatto@gmail.com; idemir@utfpr.edu.br

${ }^{2}$ Empresa de Pesquisa Agropecuária e Extensão Rural, Itajaí, Santa Catarina, Brasil. luanamaro@epagri.sc.gov.br

*Autor para correspondência: generpenso@gmail.com
} 


\section{INTRODUÇÃO}

A diversificação da produção em propriedades rurais vem sendo fomentada nos últimos anos, principalmente nas regiões sul e sudeste do Brasil. A olivicultura vem sendo testada como opção para essa diversificação. Aliado a isso, há forte apelo para o consumo de azeitonas e de azeites, pelos benefícios proporcionados à saúde (MartínPeláez et al., 2013).

O Koroneiki está entre os principais cultivares plantados mundialmente, destinado à produção de azeite, sendo esse o principal cultivar utilizado na Grécia. Seu fruto apresenta elevado teor de óleo (até 28\%), com elevado teor de polifenóis e alta estabilidade, recomendável para sistemas modernos de alta densidade (Vossen, 2007).

No Brasil, as importações, no ano de 2011, foram superiores a 156 mil toneladas entre azeitonas e azeites, perfazendo um montante de 408 milhões de dólares, principalmente de países europeus, enquanto, nesse mesmo período, foram colhidas apenas 77 toneladas de azeitonas no Brasil (Food and Agriculture Organization - FAO, 2014). Frente a esses dados, fica nítida a necessidade de investimento em pesquisas para o desenvolvimento da olivicultura no país, em toda a sua cadeia produtiva, da produção de mudas ao processamento da colheita.

Tratando-se de produção de mudas, a oliveira pode ser propagada por vários métodos. Apesar de as sementes serem viáveis, sua utilização não é vantajosa comercialmente, por originar plantas com características distintas das plantas matrizes e apresentar maior período juvenil (10 a 15 anos), atrasando o início da entrada em produção (Vossen, 2007; Oliveira et al., 2009). A propagação assexuada por estaquia é o principal método de propagação da cultura, por ser relativamente barato e prático (Caballero \& Del Rio, 1998), com vantagens sobre a propagação sexuada, pois origina plantas idênticas às plantas matrizes, com menor período juvenil e precocidade de produção (Fachinello et al., 2005). A propagação vegetativa da oliveira, no Brasil, pelo método de estaquia, ainda apresenta pequena quantidade de informações, especialmente com o cv. Koroneiki.

Como o emprego da técnica ainda não está totalmente esclarecido para as condições sul brasileiras, neste trabalho, objetivou-se identificar a melhor época para realização da estaquia, a melhor concentração de AIB e o melhor número de pares de folhas na estaquia da oliveira cv. Koroneiki (Olea europaea L.).

\section{MATERIAIS E MÉTODOS}

O experimento foi realizado na Universidade Tecnológica Federal do Paraná, UTFPR, Câmpus Pato Branco, utilizando-se o cv. Koroneiki, com material coletado de plantas de três anos de idade (estacas semilenhosas), entre junho de 2013 e março de 2014. O experimento foi conduzido no delineamento inteiramente ao acaso, com quatro repetições de dez estacas, no esquema fatorial triplo, sendo o fator A constituído por quatro épocas (junho, setembro, dezembro e março); o fator B por 0, 1 e 2 pares de folhas e, o fator $\mathrm{C}$ por quatro concentrações de $\operatorname{AIB}(0$, $1.000,2.000 \mathrm{e} 3.000 \mathrm{mg} \mathrm{L}^{-1}$ ).

As estacas foram padronizadas com $10 \mathrm{~cm}$ de comprimento, utilizando-se apenas a porção mediana dos ramos. O AIB (ácido 4,3-indolilbutírico P.S.) foi dissolvido com algumas gotas de solução alcalina $(\mathrm{NaOH} 6 \mathrm{M})$ e o volume ajustado com água destilada. Foi realizada a imersão rápida da base das estacas $(3 \mathrm{~cm})$, por cinco segundos, em solução de AIB. As estacas foram colocadas em tubetes com substrato comercial (húmus, vermiculita e casca de arroz carbonizada) e em câmara úmida, sob nebulização, com aspersão de dez segundos, em intervalos de 40 minutos. As estacas permaneceram nesse ambiente por 60 dias. Após esse período, foi realizada análise destrutiva das estacas sendo mensurados: sobrevivência (\%), formação de calos (\%, independentemente do enraizamento), número de brotos por estaca e enraizamento (\%).

Os dados foram analisados quanto à normalidade pelo teste de Shapiro-Wilk e quando não apresentaram distribuição normal foram transformados por $\sqrt{\mathbf{x}+0,5}$. As diferenças entre médias foram comparadas pelo teste de Tukey ( $p$ d" 0,05 ), com o programa R Project (R Core Team, 2012), do pacote ExpDes.pt (Ferreira; Cavalcanti \& Nogueira, 2013).

\section{RESULTADOS E DISCUSSÃO}

Observou-se interação tripla significativa para as variáveis sobrevivência $(p=0,0001)$, formação de calos $(p$ $=0,0001)$ e enraizamento $(p=0,002)$. A variável número de brotos por estaca apresentou apenas interação entre os fatores épocas e pares de folhas $(p=0,0001)$ e concentrações e pares de folhas $(p=0,003)$.

A máxima sobrevivência, próxima a 100\%, ocorreu com as estaquias realizadas em junho, setembro e março ( $F i-$ guras 1A, 1B, 1D, respectivamente), com ou sem o uso de AIB, desde que mantido pelo menos um par de folhas. Os tratamentos com ausência de folhas apresentaram percentagens de sobrevivência de estacas satisfatórias, acima de $60 \%$, somente em junho, em combinação com as maiores concentrações de AIB (2.000 e $\left.3.000 \mathrm{mg} \mathrm{L}^{-1}\right)$. Já nas demais épocas, os tratamentos com ausência de folhas apresentaram sobrevivência abaixo de 10\%. Em dezembro (Figura 1C), o tratamento com um par de folhas apresentou maior sobrevivência quando se utilizou a maior concentração de AIB $\left(3.000 \mathrm{mg} \mathrm{L}^{-1}\right)$. Nas demais épocas (setembro e março), a ausência de folhas foi prejudicial à sobrevivência, independentemente da concentração de AIB utilizada. 
A sobrevivência está intimamente ligada com as reservas da estaca, sendo que a manutenção das folhas (avaliação não realizada neste experimento) favorece a sobrevivência das estacas, pois possuem reservas de carboidratos e sua atividade metabólica é mantida por mais tempo, favorecendo a atuação e a atividade das auxinas (Fabbri et al., 2004; Fachinello et al., 2005). A ausência de folhas também pode ser prejudicial à sobrevivência pelo maior número de lesões ocasionados pela desfolha, aumentando-se os pontos passíveis de desidratação. Também, é comum em viveiros a infecção por fungos como Pythium aphanidermatum, Fusarium solani, Rhizoctonia solani e Verticillium dahliae. Esses fungos podem-se beneficiar pelo maior número de portas de infecção que levam ao declínio das estacas no estádio de enraizamento (AlKhatib, 2012).

A maior sobrevivência em junho, mesmo com a ausência de folhas, pode ser explicada pelo fato de as plantas matrizes encontrarem-se com crescimento vegetativo paralisado e, possivelmente, com alta concentração de reservas nos tecidos lenhosos. Nas demais épocas, as folhas foram responsáveis pela manutenção da atividade metabólica das estacas. Pode-se observar que, na terceira época (dezembro), houve redução da sobrevivência, mesmo quando mantidas as folhas, possivelmente por causa do intenso crescimento vegetativo da planta, utilizando parte das reservas armazenadas no período de repouso vegetativo (inverno), reduzindo o tempo de sobrevivência das estacas (Fachinello et al., 2005; Denaxa et al., 2012).

O número de brotações por estaca foi maior na primeira época (junho), com aproximadamente três brotos por estaca, porém sem diferenças significativas entre um ou dois pares de folhas, que, por sua vez, apresentaram maior brotação que com a ausência de folhas (Figura 2A). Para as demais épocas, houve variações nas respostas aos tratamentos.

$\mathrm{Na}$ interação entre as concentrações de AIB e pares de folhas, o maior número de brotações foi obtido pelos tratamentos com um par de folhas, acima de dois brotos por estaca, independentemente da concentração de AIB utilizada (Figura 2B). Quando mantido dois pares de folhas, o maior número de brotações foi observado nas concentrações de 0 e $2.000 \mathrm{mg} \mathrm{L}^{-1}$ de AIB e a maior concentração de AIB, nesse caso, reduziu o número de brotações por estaca (Figura 2B). Isso pode ter ocorrido pelo fato de que, com o menor número de folhas nas estacas, a concentração de auxina endógena era baixa, havendo resposta positiva ao aumento da concentração de auxina exógena. Porém, com dois pares de folhas, a concentração de auxina endógena pode ter sido suficiente e, com o aumento da concentração de auxina exógena, o efeito passou a ser negativo (Ismaili \& Fiku, 2010).
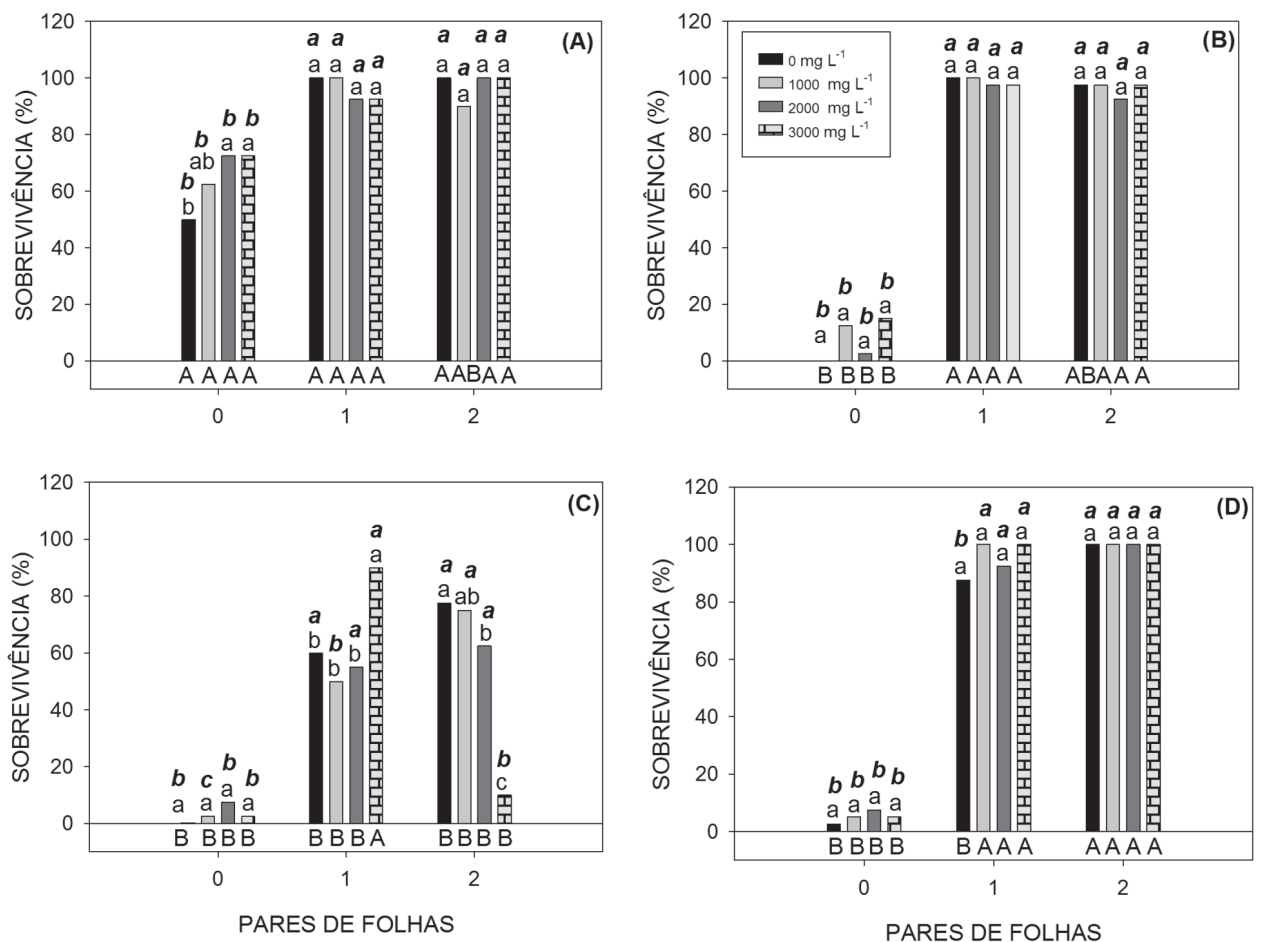

Figura 1: Percentagem de sobrevivência de estacas de oliveira cv. Koroneiki nas estaquias realizadas em junho (A), setembro (B), dezembro (C) e março (D), mantendo-se 0,1 e 2 pares de folhas, tratadas com 0, 1.000, 2.000 e $3.000 \mathrm{mg} \mathrm{L}^{-1}$ de AIB. Letras maiúsculas comparam diferentes épocas de estaquia (A; B; C; D) na mesma concentração de AIB e par de folhas. Letras minúsculas em itálico e negrito comparam diferentes pares de folhas na mesma concentração de AIB e época de estaquia. Letras minúsculas comparam diferentes concentrações de AIB na mesma época de estaquia e pares de folhas. Tratamentos com letras distintas diferem entre si pelo teste de Tukey $(p \leq 0,05)$. 
$\mathrm{Na}$ avaliação da percentagem de formação de calos (independentemente do enraizamento), os melhores resultados foram obtidos nos tratamentos com a presença de folhas, principalmente na segunda e quarta épocas, com percentagens próximas a 100\% (Figuras 3B e 3D, respectivamente).
A estaquia em dezembro foi a que apresentou menor percentagem de formação de calos, abaixo de $60 \%$ mesmo com a presença de folhas e nas maiores concentrações de AIB (Figura 3C). Em junho, as estacas com ausência de folhas apresentaram maior percentagem de formação de calos com o aumento da concentração de AIB. Nas de-
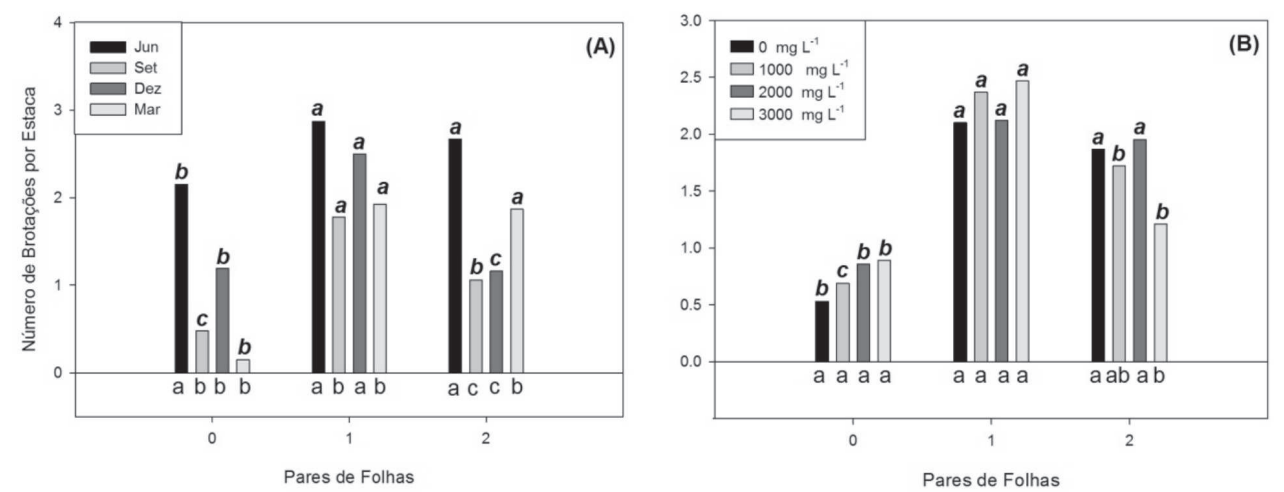

Figura 2: Número de brotações por estacas de oliveira cv. Koroneiki nas estaquias realizadas em junho, setembro, dezembro e março, mantendo-se 0,1 e 2 pares de folhas (A); Número de brotações por estacas de oliveira cultivar Koroneiki mantidas com 0,1 e 2 pares de folhas e tratadas com 0, 1000, 2000 e $3000 \mathrm{mg} \mathrm{L}^{-1}$ de AIB (B). Letras minúsculas abaixo das barras em (A) comparam a mesmo número de pares de folhas nas diferentes épocas. Letras minúsculas em negrito e em itálico acima das barras comparam mesma época nos diferentes números de pares de folhas. Letras minúsculas abaixo das barras em (B) comparam as diferentes concentrações de AIB em mesmos números de pares de folhas. Letras minúsculas em itálico acima das barras comparam mesma concentração de AIB nos diferentes números de pares de folhas. Em todos os conjuntos, tratamentos com letras distintas diferem entre si pelo teste de Tukey $(p \leq 0,05)$.
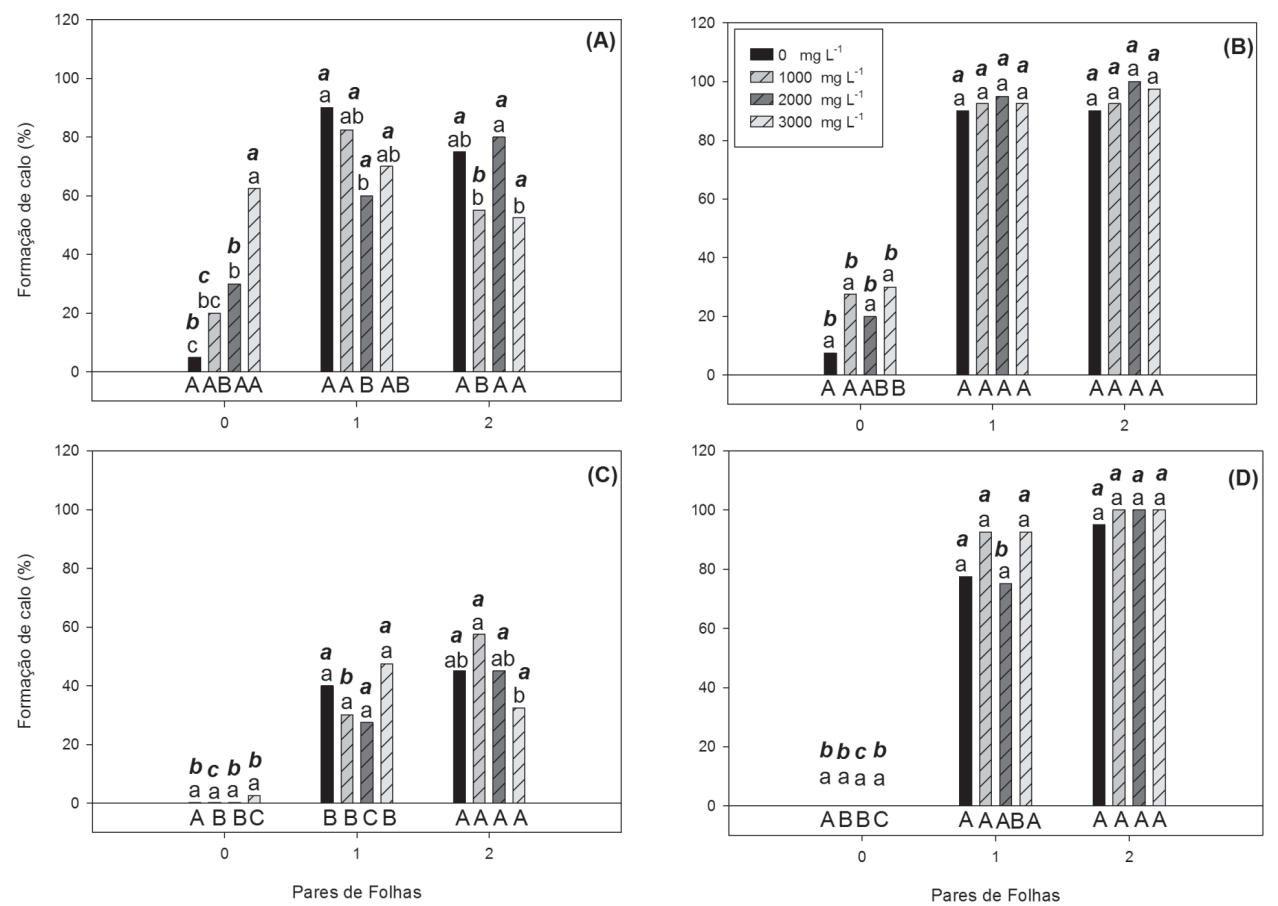

Figura 3: Percentagem de formação de calos de estacas de oliveira cv. Koroneiki nas estaquias realizadas em junho (A), setembro (B), dezembro (C) e março (D), mantendo 0, 1 e 2 pares de folhas tratadas com 0, 1000, 2000 e $3000 \mathrm{mg} \mathrm{L}^{-1}$ de AIB. Letras maiúsculas comparam diferentes épocas de estaquia (A; B; C; D) na mesma concentração de AIB e mesmo número de pares de folhas. Letras minúsculas em itálico e negrito comparam diferentes números de pares de folhas na mesma concentração de AIB e mesma época de estaquia. Letras minúsculas comparam diferentes concentrações de AIB na mesma época de estaquia e número de pares de folhas. Tratamentos com letras distintas diferem entre si pelo teste de Tukey $(p \leq 0,05)$. 
mais épocas, mesmo com o aumento da concentração de AIB, para as estacas sem folhas, não houve a presença de calos, sendo a percentagem próxima ou igual a $0 \%$. A percentagem máxima de formação de calos foi superior aos resultados de Oliveira et al. (2009), em que os autores apresentam percentagem máxima de formação de calos de 19\%, utilizando as mesmas concentrações de AIB.

Segundo Fachinello et al. (2005), estacas coletadas no período de inverno apresentam maior grau de lignificação, resultando em possível dificuldade de formação de calos e, consequentemente, de raízes, pela dificuldade da modificação dos tecidos. Já quando as estacas são coletadas no período do verão, com baixo grau de lignificação, são mais susceptíveis à desidratação, bem como, pela menor quantidade de reservas, a formação de calo é prejudicada. Os resultados obtidos, portanto, são compatíveis com os relatos desses autores, que apontam os períodos intermediários, utilizando-se estacas semilenhosas, como ideais para a formação de calos.

Os resultados obtidos permitem inferir que a manutenção das folhas e das atividades metabólicas aumenta a formação de calos, independentemente da concentração de AIB, para estacas classificadas como semilenhosas (setembro e março), evidenciando que a concentração de auxina endógena, nesses casos, é suficiente para estimu-
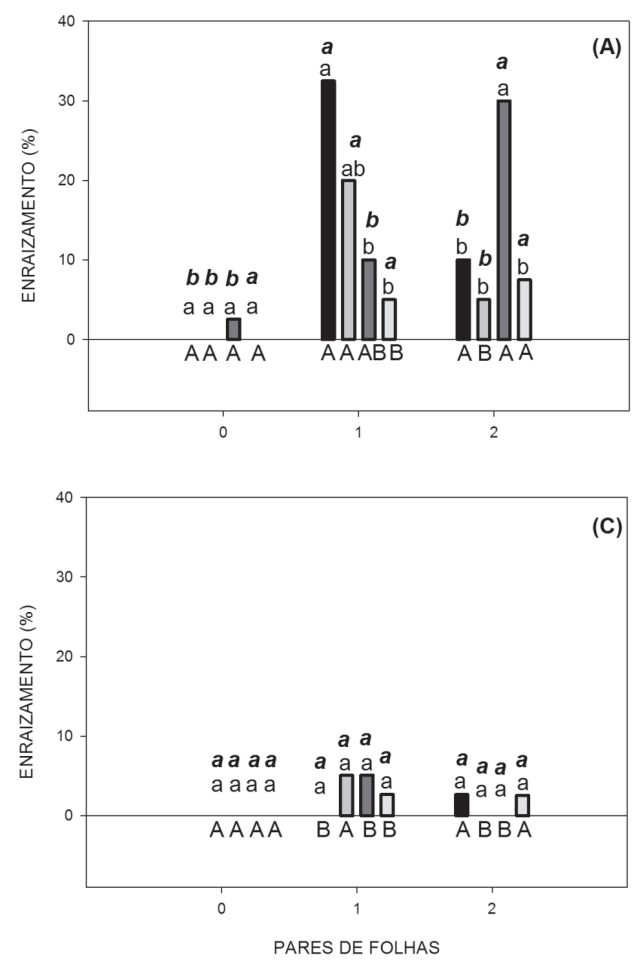

lar a diferenciação do tecido e consequente formação de calos (Ismaili \& Lani, 2013). Porém, os resultados obtidos com a estaquia em junho (Figura 3 A), com a manutenção de um par de folhas, mostram que o aumento da concentração de AIB exógeno prejudica a formação de calos.

A capacidade de formação de calos é indicativa de capacidade de transformação e diferenciação dos tecidos e, segundo Fachinello et al. (2005), o calo aparece no tecido lesionado, resultando em posterior formação de um tecido de cicatrização, constituído por uma massa de células parenquimatosas, desorganizadas e em diferentes etapas de lignificação. Entretanto, muitos autores consideram a formação de calos e a de raízes como processos totalmente independentes e que, por vezes, a formação de excesso de calos pode até mesmo impedir a formação de raízes, mas, frequentemente, as raízes aparecem após a formação de calos, por meio da diferenciação das células parenquimatosas formadas a partir deles (Hartmann \& Kester, 1990; Silva \& Pereira, 2004).

O cultivar Koroneiki é considerado de fácil e rápido enraizamento (Hechmi et al., 2013). Neste trabalho, a percentagem máxima de enraizamento ficou próxima a $40 \%$ e pode ser considerada baixa, quando comparada com dados obtidos por outros autores (Oliveira et al., 2009; Pio et al., 2005).
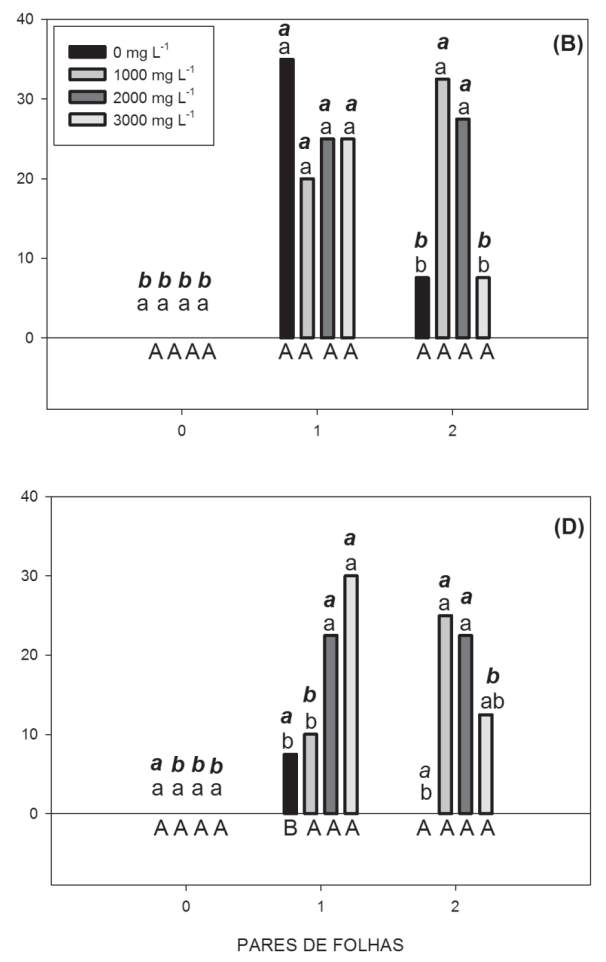

Figura 4: Percentagem de enraizamento de estacas de oliveira cv. Koroneiki nas estaquias realizadas em junho (A), setembro (B), dezembro (C) e março (D), mantendo-se 0, 1 e 2 pares de folhas, tratadas com 0, 1000, 2000 e $3000 \mathrm{mg} \mathrm{L}^{-1}$ de AIB. Letras maiúsculas comparam diferentes épocas de estaquia (A; B; C; D) na mesma concentração de AIB e mesmo número de pares de folhas. Letras minúsculas em itálico e negrito comparam diferentes números de pares de folhas na mesma concentração de AIB e época de estaquia. Letras minúsculas comparam diferentes concentrações de AIB na mesma época de estaquia e mesmo número de pares de folhas. Tratamentos com letras distintas diferem entre si pelo teste de Tukey $(p \leq 0,05)$. 
$\mathrm{Na}$ ausência de folhas, observou-se que a percentagem de enraizamento foi praticamente nula, em todas as concentrações de AIB e épocas de estaquia (Figura 4) sendo esses resultados muito inferiores aos obtidos por Pio et al. (2005), que observaram percentagem de enraizamento de estacas de oliveiras 'Grapollo' próxima a 40\%, mesmo em estacas sem presença de folhas e em concentrações de AIB até $3.000 \mathrm{mg} \mathrm{L}^{-1}$. Na estaquia em junho, com apenas um par de folhas, o aumento da concentração de AIB reduziu a formação de raízes, sendo a maior percentagem encontrada quando as estacas não foram tratadas. Quando mantidos dois pares de folhas, nessa mesma época, o maior enraizamento ocorreu com $2.000 \mathrm{mg} \mathrm{L}^{-1}$ (Figura 4A). Na estaquia em setembro, o aumento da concentração de AIB também mostrou tendência de reduzir o enraizamento em estacas com um par de folhas. Com a utilização de dois pares de folhas, as maiores percentagens de enraizamento foram obtidas com as concentrações de $1.000 \mathrm{e}$ $2.000 \mathrm{mg} \mathrm{L}^{-1}$ (Figura 4B). Essas mesmas concentrações promoveram a maior percentagem de enraizamento na estaquia em dezembro, porém, quando mantido apenas um par de folhas (Figura 4C). Na quarta época (março), com um par de folhas, o aumento das concentrações de AIB promoveu aumento do enraizamento, sendo maior com $3.000 \mathrm{mg} \mathrm{L}^{-1}$. Por sua vez, quando mantidos dois pares de folhas, o aumento da dose de AIB reduziu a formação de raízes (Figura 4D).

Em geral, pode-se observar que para essas condições houve baixa percentagem de enraizamento de estacas, próxima a $40 \%$, sendo que dados de literatura apresentam percentagens de enraizamento para a cultura da oliveira acima de $70 \%$, com utilização de nebulização intermitente e uso de AIB em concentração de $3.000 \mathrm{mg} \mathrm{L}^{-1}$, como apresentado por Ismaili \& Lani (2013). Ismaili \& Fiku (2011) também apresentam elevada percentagem de enraizamento de estacas de oliveira, acima de 70\%, também utilizando câmara de nebulização intermitente e concentrações de AIB de $5.000 \mathrm{mg} \mathrm{L}^{-1}$ em quatro épocas do ano.

\section{CONCLUSÕES}

Para a maior sobrevivência, formação de calos e enraizamento da oliveira cv. Koroneiki é necessária a manutenção de, pelo menos, um par de folhas nas estacas.

A estaquia em dezembro não é recomendada, independentemente das técnicas auxiliares utilizadas.

Sem a utilização de AIB, recomenda-se realizar a estaquia em junho e setembro, desde que mantido um par de folhas.

Na estaquia em março, deve-se manter pelo menos um par de folhas, em combinação com doses de 2.000 ou 3.000 $\mathrm{mg} \mathrm{L}^{-1}$ de AIB.

\section{REFERÊNCIAS}

AL-Khatib M (2012) Fungal diseases of olive cuttings in the rooting stage in Jordan. Research Journal of Biological Sciences, 7:8:297301 .

Caballero JM \& Del Rio C (1998) Métodos de multiplicación. In: Barranco D, Fernandez-Escobar R \& Rallo (Eds.) El cultivo del olivo. $2^{\mathrm{a}}$ ed. Madri, Junta de Andalucia/Mundi-Prensa. 651p.

Denaxa NK, Vemmos SN \& Roussos PA (2012) The role of endogenous carbohydrates and seasonal variation in rooting ability of cuttings of an easy and a hard to root olive cultivars (Olea europaea L.). Scientia Horticulturae, 143:19-28.

Fabbri A, Bartolini G, Lambardi M \& Kailis SG (2004) Olive propagation manual. Camberra, CSIRO Publishing. 3066p.

Fachinello JC, Hoffmann A \& Nachigal JC (2005) Propagação de plantas frutíferas. Brasília, Embrapa Informação Tecnológica. $221 \mathrm{p}$.

FAO - Food And Agriculture Organization of The United Nation (2014) Pesquisa de produção por países entre os anos de 1993 a 2013. Disponível em: <http://faostat.fao.org>. Acesso em:14 de julho de 2014.

Ferreira EB, Cavalcanti PP \& Nogueira DA (2013) ExpDes: Experimental Designs pacakge. Disponível em: <http://cran.rproject.org/web/packages/ExpDes/index.html>. Acessado em: 02 de março de 2014.

Hartmann HT \& Kester DE (1990) Propagación de plantas principios y practicas. México, Compañia Editorial Continental. 760 p.

Hechmi M, Khaled M, Abed S, EL-Hassen A, Faiez R \& Mhamed A (2013) Performance of olive cuttings (Olea europaea L.) of different cultivars growing in the agro-climatic conditions of Al-Jouf (Saudi Arabia). American Journal of Plant Physiology, $8: 41-49$

Ismaili H \& Fiku H (2010) Olive cultivar propagation based on nebulization method. Albanian journal agricultural scientia, 10:2218-2020.

Ismaili H \& Lani V (2013) The Study of rhizogenesis in the vegetative sprigof the olive (Olea europea L.) through the method of mist propagation. Albanian journal agricultural scientia, 12:283-287.

Martín Peláez S, Covas MI, Fitó M, Kušar A \& Pravst I (2013) Health effects of olive oil polyphenols: recent advances and possibilities for the use of health claims. Molecular nutrition and food research, 57:760-771.

Oliveira AF de, Chalfun NNJ, Alvarenga AA, Vieira JN, Pio R \& Oliveira DL (2009) Estaquia de oliveira em diferentes épocas, substratos e doses de AIB diluído em $\mathrm{NaOH}$ e álcool. Ciência Agrotécnica, 33:79-85.

Pio R, Bastos DC, Berti AJ, Scarpare Filho JA, Mourão Filho FAA, Entelmann FA, Alves ASR \& Bettiol Neto JE (2005) Enraizamento de diferentes tipos de estacas de oliveira (Olea europea L.) utilizando ácido indolbutírico. Ciência Agrotécnica, 29:562-567.

R Core Team R (2012) A Language and Environment for Statistical Computing. Disponível em: <http://www.r-project.org/>. Acessado em: 02 de março de 2014.

Silva JAA \& Pereira FM (2004) Enraizamento de estacas herbáceas de nespereira (Eriobotrya japonica LindiI). Revista Brasileira de Fruticultura, 26:369-371.

Vossen P (2007) Olive oil: history, production, and characteristics of the world's classic oils. HortScience, 42:1093-1100. 